\title{
Resistance of Bonded Composite
} Joints to Out-Of-Plane Forces

Ronald E. Allred, Tommy R. Guess

When printing a copy of any digitized SAND Report, you are required to update the markings to current standards. 
Issued by Sandia Laboratories, operated for the United States Energy Research and Development Administration by Sandia Corporation.

\section{NOTICE}

This report was prepared as an account of work sponsored by the United States Government. Neither the United States nor the United States Energy Research and Development Administration, nor any of their employees, nor any of their contractors, subcontractors, or their employees, makes any warranty, express or implied, or assumes any legal liability or responsibility for the accuracy, completeness or usefulness of any information, apparatus, product or process disclosed, or represents that its use would not infringe privately owned rights.

Printed in the United States of America Available From

National Technical Information Service

U. S. Department of Commerce

5284 Port Royal Road

Springfield, VA 22151

Price: Printed Copy $\$ 5.00$; Microfiche $\$ 2.25$ 


\section{SAND75-0460}

RESISTANCE OF BONDED COMPOSITE JOINTS

TO OUT-OF-PIAINE FORCES

R. E. Allred and T. R. Guess

Sandia Laboratories, Albuquerque, New Mexico 87115

March 1976

An analytical and experimental study was conducted to examine the mechanical behavior of double-lapped adhesive-bonded joints subjected to bending loads. Adherends consisted of a U-shaped high-strength steel hub and a unidirectional composite of either B/AI or B/epoxy. Adhesives with a range of moduli and peel strengths were evaluated with and without bolts in regions of high stress concentration.

Finite element analyses indicated high shear and normal stress concentrations at the end of the steel hub legs. These concentrations are a direct function of the effective hub stiffness-increases in hub thickness or Young's modulus result in higher adhesive stresses. Stress concentrations in the adhesive layer may be reduced by decreasing adhesive modulus, composite transverse modulus, or composite in-plane shear modulus.

Experimental testing of sample joints revealed that failure modes are controlled by the composite adherend material. Joints incorporating a $B / A I$ adherend failed by adhesive peel in the region of high stress concentration. Failure occurred at a load level which stressed the B/AI composite to 75 percent of its $200 \mathrm{ksi}$ ( $1517 \mathrm{MPa}$ ) ultimate strength. 
Delamination of the $B /$ epoxy composite was the predominant failure mode of joints utilizing a B/epoxy adherend. Failure by delamination was suppressed by the insertion of high-strength bolts into the stress concentration region. These bonded and bolted joints reached 68 percent of the composite bending strength (220 ksi, $1517 \mathrm{MPa}$ ). 
TABLE OF CONTENTS

PAGE

List of Tables..................................... 4

List of Figures..................................... 4

Introduction...................................... 5

Analytical Predictions of Adhesive Stress Distributions........ 7

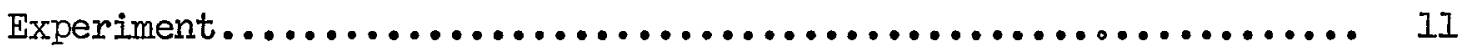

Results and Discussion............................ 13

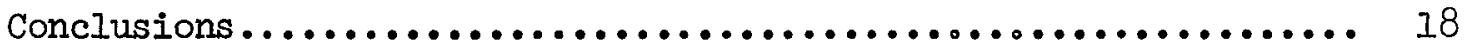

References....................................... 29 
LIST OF TABIES

TABLE

PAGE

I Elastic Material Properties Used in Analysis 19

II Summary of Maximum Adhesive Stresses in Subscale Fin. Results Are for the Specific Boundary Conditions Shown in Figure 2.

III Summary of Maximum Stresses in Adhesive for FullSized Fins with the Geometries and Boundary Conditions Illustrated in Figure 5.

\section{IIST OF FIGURES}

Predicted stress distributions for adhesive-bonded double-lapped steel-B/Al joint subjected to 1000 psi bending stress on outer fibers.

4 Predicted stress distributions for adhesive-bonded double-lapped steel-B/epoxy joints subjected to 1000 psi stress on outer fibers.

Finite element meshing schemes for full-sized joints. 26 Composite thickness $=0.40$ in., adhesive thickness $=0.010 \mathrm{in}$. , bond length $=4.0 \mathrm{in} .$, and boundary conditions same for both. Hub wall thickness only geometrical variable in (a) 0.125 in. and in (b) $0.50 \mathrm{in.}$

Fracture surface of adhesive bonded (EC-2214R) and bolted B/AI fin in airfoil geometry.

Delamination fracture surface of bonded (EC-22l4R) and bolted joint with B/epoxy fin. 


\section{Introduction}

The use of deployable tail fins for a maneuvering capability in the FUFO-GIADD program has stimulated the investigation of high-performance composites as fin materials. Potential advantages of increased strength, reduced deflections and substantial weight savings over alternate materials such as titanium are shown by unidirectional composites [1]. These benefits, however, are contingent upon the development of a structural joint between the airfoil fin and actuator mechanism. A one-piece composite fin within the actuator cannot be used due to the complex and severe stress state and irregular shape necessary in the hub region [I]. Thus, a retention member (hub) between the composite fin and actuator is required. Highstrength steel is the most attractive material for this purpose. The problem is then to obtain a structural joint capable of transferring the large bending loads imposed upon the composite control surface to the metal hub.

Structural joints, which pose many design limitations with homogeneous, isotropic materials, are further complicated by the anisotropy of composite adherends. One limitation imposed by composite adherends is that most conventional metal joining methods are inapplicable. This is particularly true for resin-matrix composites. Thus, only mechanical (riveting or bolting) or adhesive techniques are available to join these materials. The mechanical methods can present serious disadvantages for unidirectional composites in terms of stress concentration effects [2]. It appears, then, that adhesive bonding may be the most desirable method of joining composite materials. 
The majority of structural adhesive joining techniques have been developed for tensile or compressive-shear joints. These are the most efficient methods of transferring large loads; however, it is sometimes necessary to utilize an alternate loading geometry, as in the FUFO-GLADD fin. Here, bending loads are applied to the joint from the application of a pressure distribution along the length of the fin. Any adhesive joint configuration is inefficient in bending due to the development of high normal or peel stresses; of these, the double-lap joint used here appears the most favorable for bending applications [3].

The specific fin-joint geometry of interest is shown schematically in Figure 1. The airfoil fin, normally seated inside the stationary T-fin, is shown in the deployed condition. Deployment is achieved by rotation about the pin connection. Composite and hub thickness are dictated by the T-fin opening. Loads from the composite airfoil are transmitted through the adhesive to the metal hub, from the hub to the T-fin and finally into the case.

The objective of this study was to determine the adhesive-composite combination capable of supporting the highest bending load in the geometry given in Figure 2. Boron/aluminum and boron/epoxy composite systems were chosen for evaluation primarily because of their high specific bending stiffness and strength. The approach taken was first to analytically model the joint, specifically to calculate the magnitude and distribution of stresses in the adhesive. Parametric studies were then conducted with the variables of composite, hub and 
adhesive elastic properties. Trends in the stress state as a function of material properties may be used to design the optimum joint for the bending enviromment. These predicted trends were investigated experimentally for verification and to determine failure modes and joint load-carrying capacity. The effect of mechanical fasteners in regions of high predicted stress was also examined.

\section{Analytical Predictions of Adhesive Stress Distributions}

A finite element computer code, SAAS IIa, was utilized for determining the static stresses and strains occurring in the joint. SAAS IIa is a FORTRAN program designed for the Stress Analysis of Axisymmetric Solids and is a revised version of the program described in Reference 4. The program can also be used for the solution of plane structures, as was the case for this study. The code features a finite element mesh generation option and allows up to six separate anisotropic (orthotropic) materials. Average values of stresses and strains are computed at the centroid of each element.

The composite airfoil-metal hub joint of interest and the pertinent supporting portion of the I-fin were divided into quadrilateral elements by means of the meshing scheme shown in Figure 2. The adhesive joint was meshed to be one element in thickness and 30 elements in length. AlI boundaries are free except two: (I) the attachment region of the metal hub is modeled as having fixed displacement boundary conditions, 
i.e., the $R$ and $Z$ coordinate displacements are zero, and (2) the end of the composite fin has stress boundary conditions that simulate stresses induced by aerodynamic loading (see Figure 2). The entire length of the composite is not modeled and since the solution is for plane strain assumptions, the composite width is not considered.

Coordinates and stresses of interest are defined in Figure 2. The principal results sought are the normal and shear stresses in the adhesive layer, $\sigma_{\mathrm{R}}$ and $\tau_{\mathrm{RZ}}$. The magnitude of these stresses and their distribution along the bond line of length $\ell$ are described in terms of $\mathrm{z} / \ell$, the coordinate position along the joint from the entrance of the composite into the metal hub.

The first set of calculations performed with the SAAS IIa code was aimed at determining the effect of composite and adhesive elastic properties on the stresses in the adhesive layer. Elastic properties of the two composite systems (B/Al and B/epoxy) and two structural adhesives (EC-2214R and Chemlok 304; these adhesives will be described later) are given in Table I. For economic reasons, test specimens used in the experimental portion of this study were fabricated to one-third scale (except for bond thickness which remained at 0.007 in. $(0.178 \mathrm{~mm}$ )) of the fin dimensions given in Figure 1. The model shown in Figure 2 matches the size of the test parts; therefore, the analytical and experimental results are directly comparable.

The adhesive stresses $\sigma_{R}$ and $\tau_{R Z}$ as a function of $z / l$ for four adhesive-composite combinations with steel supporting members are 
illustrated in Figures 3 and 4. The adhesive stresses are calculated for the stress and displacement boundary conditions shown in Figure 2 . These results are for the upper bond line where $\sigma_{R}$ is tensile (peel stresses generated) in the vicinity of $\mathrm{z} / \ell=0$. This is the bond line of interest because failure will occur in it rather than the lower one where $\sigma_{\mathrm{R}}$ is compressive. Since the analysis is linear, stresses in the joint can be determined for any magnitude of stress boundary condition simply by scaling with respect to the 1000-psi (6.89 MPa) outer fiber stresses used here, provided the ratio of bending to shear stress is equivalent to that shown in Figure 2.

The maximum values of $\sigma_{R}$ and $\tau_{R Z}$ in Figures 3 and 4 occurred in the first element of the adhesive near $\mathrm{z} / \mathrm{l}=0$. The absolute values of these stresses are questionable because computed stresses are dependent on mesh size in the regions of high-stress gradients and/or singularities. However, relative values or trends for different composite/adhesive combinations should be accurate. These trends are seen in Table II, where $\sigma_{R}$, the extrapolated value at $\mathrm{Z} / \ell=0$, and $\tau_{R Z}$, the value at the centroid of the first adhesive element $(\mathrm{z} / \mathrm{l}=0.0167)$, are given in tabular form. The stress concentrations at the end of the retention member may be anticipated from this loading geometry; however, the large magnitudes of the concentrations provide an especially severe stress state for an adhesive bond.

The SAAS IIa code was also used to analyze joints of larger component geometries but with an adhesive bond thickness similar to 
that of the smaller joints just described. The two new geometries are shown in Figure 5. Note that these models do not include the T-fin support member. The purpose of this set of computations was to determine the effect on maximum $\sigma_{R}$ and $\tau_{R Z}$ of three variables: (1) elastic properties of the metal retention member, (2) thickness of the U-channel legs of the retention member and (3) the elastic properties of the composite airfoil. Only one adhesive, EC-2214R, was considered. The stress boundary conditions (Figure 5) were the same as before, except approximated over fewer elements in the composite. The elastic properties of two additional hub materials, titanium and aluminum, are also listed in Table $I$. Numerical results, $\sigma_{R}$ at $\mathrm{Z} / \mathrm{l}=0.0$ and $\tau_{R Z}$ at $\mathrm{Z} / \ell=0.0125$, are given in Table III。

Several conclusions regarding the stress concentrations in the adhesive layer and possible methods of reducing these concentrations may be drawn from the numerical results given in Tables II and III. First, the magnitude of the concentration is directly dependent upon the stiffness of the hub legs. An increase in compliance either by a thickness reduction or a material change results in lower adhesive stress. The stress concentration may be further reduced by choosing a low-modulus adhesive such as the Chemlok system which presumably can yield and redistribute the high loads. A decrease in composite transverse and shear modulus $\left(E_{R R}\right.$ and $\left.G_{R Z}\right)$ from the $B / A I$ to the $B /$ epoxy system also results in lower adhesive stresses.

These results were used as guidelines to pick a geometry and adhesives for use in the experimental testing program. Of particular 
interest are the verification of the predicted stress concentrations and the trends toward lower resultant stresses when adhesive stiffness or composite transverse stiffness are reduced.

\section{Experiment}

The experimental testing program of the composite airfoil-metal hub joint was aimed at three areas of interest: (1) to characterize the composite fin in the airfoil shape, (2) to examine the mechanical behavior of adhesive-bonded fin-hub joints, and (3) to determine the effect of bolts in the high normal stress region of the adhesive joint. For this purpose, the experimental joining study was conducted with a fixed geometry and hub material. Permutations of the two unidirectionalreinforced composite systems and three structural adhesives were incorporated into the sample joints. All tests were conducted on subscale specimens, one-third the size shown in Figure 1.

The $B / A$ I used in this study consisted of 50 volume percent 0.0056 in. $(0.142 \mathrm{~mm}$ ) diameter filaments in a 6061-F matrix as manufactured by Amercom, Inc. The resin-matrix composites were fabricated at Sandia Iaboratories by hot pressing preimpregnated tape layups in matched die molds. The prepregs consisted of 0.0056 in. $(0.142 \mathrm{~mm}$ ) boron in PR-286 epoxy resin (SP-296 system, 3M Co.). The laminates were pressed to stops while following the manufacturer's recommended cure cycle to a final temperature of $177^{\circ} \mathrm{C}$. The resultant filament volume fraction was 50 percent. Composite mechanical properties were characterized on subscale fin specimens machined to the airfoil shape and tested in bending. Rectangular 
bars 8.0 in. $(203.2 \mathrm{~mm}) \times 1.33$ in. $(33.78 \mathrm{~mm}) \times 0.236$ in. $(5.994 \mathrm{~mm})$ were ground from the composite plates for use as the composite ahderends in part of the experimental joining program.

Hubs were machined from 4130 steel and heat-treated to Rockwell 445. The U-channel was machined to 0.250 in $(6.350 \mathrm{~mm})$ to allow a $0.007-$ in. $(0.178 \mathrm{~mm})$ adhesive bond line. A wall thickness of $0.40 \mathrm{in}$. (1.016 mm) remained as each leg of the U-channel. Prior to bonding, each hub was degreased in trichloroethylene vapor and sandblasted, followed by dusting with Freon. The composite fins were also abraded prior to bonding with a light sandblast or sandpaper, again followed by dusting. Bonding was accomplished in a specially designed jig which centered the composite in the hub U-channel and aligned the fin-hub leading edge.

Three structural adhesives were chosen to provide a wide range of adhesive mechanical properties: (I) EC-2214R (I part paste), 3M Co., (2) FM-53U (film), American Cyanamid and (3) Chemlok 304 (2 parts paste 1:I), Hughson Chemicals. Both the composite and hub were coated with the paste adhesives before introducing the composite into the hub in the bonding fixture. The film adhesive was wrapped around the composite, softened with a heat gun and forced into the hub. Each of the composite systems was bonded into a retention hub with Chemlok 304 and EC-2214R. The Chemlok 304 joints were cured for 24 hours at room temperature prior to testing. Joints bonded with EC-2214R were cured at $82^{\circ} \mathrm{C}$ for 16 hours and slowly cooled to ambient before testing. A single fin of B/AI was bonded with the FM-53U film and cured for 16 hours at $80^{\circ} \mathrm{C}$. Final cure 
temperatures were held as low as possible to minimize possible residual stresses due to the thermal expansion mismatches between the joint components.

Sample joints were also fabricated with bolts in the region of high normal stress where the composite enters the hub. The bolts used were $4-40$ socket head cap screws (0.085 in. ( $2.045 \mathrm{~mm}$ ) diameter, nominal $120 \mathrm{ksi}(8.27 \mathrm{MPa})$ strength). Sleeves were incorporated where the bolt passed through the composite to avoid thread-induced stress concentrations. Bolt holes were ground in the joints after adhesive bonding and the bolts torqued to 15 in. $-1 \mathrm{~b}(1.7 \mathrm{~N} \cdot \mathrm{m})$ 。

Joint specimens were tested on a screw-driven Instron machine. Samples were pinned in a bend fixture designed to simulate the T-fin support structure (Figure 1). Bending loads were applied to the fin 2.1 in. $(53.3 \mathrm{~mm})$ from the end of the hub U-channel legs as a simulation of the lifting moment on the fin length. Deflection was applied at a rate of $0.04 \mathrm{in.} / \mathrm{min}(1.02 \mathrm{~mm} / \mathrm{min})$.

Results and Discussion

The behavior of the double-lapped joints was a strong function of the composite material used as the inner adherend. In general, the low transverse strength of the B/epoxy tended to control joint failures while the B/Al joints failed in the adhesive bond. The experimental data are given in Tables $I V$ and $V$ 。 
A joint load-carrying capacity stressing the B/Al airfoil fin to 75 percent of ultimate strength was achieved with two adhesive systems (EC-2214R and FM-53U), as seen in Table IV. These operating levels are surprisingly high in light of the severe stress concentrations on the adhesive layer in this geometry. All the adhesive-bonded joints were characterized by an initial peel failure, generally at the adhesive-steel interface. The crack progressed to a cohesive mode shortly after the peel initiation in the EC-2214R and FM-53U systems while the Chemlok 304 peeled from the steel hub along its entire length. The appearance of an EC-22I4R fracture surface revealing the initial peel mode is seen in Figure 6. The bolt holes seen in Figure 6 were drilled after the adhesive joint was tested to failure. Also seen in Figure 6 is the machined airfoil shape of a $1.375-$ in $(35 \mathrm{~mm})$ wide B/AI fin.

The result of the introduction of bolts into the highly stressed region of the joint was inconclusive with the B/Al fins (Table IV)。 The first specimen tested had previously been tested as an EC-2214R adhesivebonded joint. Three bolts were inserted through the broken hub-adhesivefin joint and torqued to $15 \mathrm{in.-1b}(1.7 \mathrm{~N} \cdot \mathrm{m})$. Upon testing in bending, the composite fajled in tension across the bolt holes at 73 percent of ultimate stress in the fin. A bending analysis of the composite fin on the net-section area across the bolt holes predicts failure at 77 percent of the composite ultimate strength based upon the original area. The close agreement between theory and experiment indicates that there is little or no stress concentration effect from the holes in the B/AI composite for this loading geometry. Placing two bolts rather 
than the three tested should result in composite failure at a level 85 percent of original.

Sample bonded and bolted joints of this type failed in the bolts at low loads $594 \mathrm{Ib}(2648 \mathrm{~N})$. The socket head cap screws used should carry $616 \mathrm{lb}(2746 \mathrm{~N})$ each in tension. Failure at the lower loads is indicative of the complex tension-shear stress state in the joint at the bolt location. Because of the bolt failure, it cannot be ascertained as to whether the peel mode could be suppressed in the high-peel systems, allowing the joint to carry an additonal load. It may be noted, however, that peel was suppressed in the low-peel adhesive system (Chemlok 304) up to bolt failure, an increase of 13 percent.

The B/epoxy adherend joints bonded with the high-peel EC-2214R adhesive all failed at a value 60 percent of the composite ultimate by a composite delamination between the first two plies. Joints bonded with the low-peel adhesive, Chemlok 304, failed by the peel mode at a lower load (Table V) which was equivalent to that in the B/Al fin joints (Table IV).

The addition of bolts to the stress concentration region of the B/epoxy fin joints was more successful than in the B/AI fin joints。 Here the bolts were able to suppress the delamination and peel modes to higher load levels. The Chemlok 304 joints with bolts still failed by peel at the adhesive-steel interface, but were able to sustain a 25 percent higher load to a composite stress 59 percent of ultimate. 
The EC-2214R bonded and bolted B/epoxy fin joints exhibited two positive points (Table V). Delamination of the composite adherend was suppressed to 68 percent of composite ultimate in bending, an increase in load of 13 percent to 653 lb (2912 N). Delamination again occurred between the first and second plies of the B/epoxy composite, as seen in the failure surface photographs presented in Figures 7 and 8. Figure 7 shows the clean boron fibers of the second ply after delamination. Also shown are the metal sleeve inserts in the bolt holes. The first layer of filaments which remained with the adhesive and steel adherend is seen in Figure 8 .

The $653 \mathrm{Ib}(2912 \mathrm{~N})$ Ioad is 55-66 Ib (245-294 N) higher than the levels at which the bolts failed in the B/Al fin joints. The bolts in that $\mathrm{B} /$ epoxy fin joint were torqued to $20 \mathrm{in} .-1 \mathrm{~b}(2.6 \mathrm{~N} \cdot \mathrm{m})$ rather than the $15 \mathrm{in.-1b}(1.7 \mathrm{~N} \cdot \mathrm{m})$ applied to the bolts in all other joints. Apparently, the higher torque reduced the bending shear loads on the bolts in favor of higher tension loads, which is a more favorable stress-state.

Even with the improved performance of the bolts, the B/epoxy fin joints were less efficient than the bonded B/AI fin joints. This is due to the delamination failure mode in the B/epoxy. Failure initiated at the end of the hub and propagated along the joint. The taper on the hub (Figure 8) prevented placement of the bolts nearer the region of highest stress. While the taper reduces the stress concentration in an adhesive-bonded joint [3], elimination of the taper, allowing place- 
ment of the bolts nearer the end of the hub, should reduce the stresses on the composite and adhesive in this case.

The fact that all failures occurred near the open end of the U-shaped hub verifies the analytical prediction that this is the region of high stress concentrations. However, the experimental data were not sufficient to verify the analytical predictions of reduced stress concentrations for joints with lower adhesive modulus and/or lower composite transverse and shear moduli. No correlation of experimental results and analytical results could be made because the failures occurred outside the adhesive layer (by interface peel or composite delamination), whereas the code calculations were for stress magnitudes in the adhesive.

The only data available that attempts to compare the resistance of adhesives to interface peel failures are from the T-peel test. These data are strongly influenced by adherend material and surface preparation techniques and, as such, may vary to a large extent. For example, manufacturers' literature $[6,7]$ values of T-peel strengths for the EC-2214R and FM-53U are $50 \mathrm{lb} / \mathrm{in.-width}(8755 \mathrm{~N} / \mathrm{m})$ and $85 \mathrm{Ib} / \mathrm{in.-}$ width $(14,884 \mathrm{~N} / \mathrm{m})$, respectively. In the tests of bonded joints presented in this work which failed by peel, these two adhesives peeled at nearly equivalent loads (Table IV)。The FM-53U, which has a lower modulus and a 70 percent higher rated peel strength, should have been significantly better in this loading environment. Because of the lack of correlation with manufacturers' peel values, it cannot be concluded whether or not T-peel data provide a useful guide in the selection of adhesives for peel applications such as bonded joints subjected to bending loads. 


\section{Conclusions}

The analytical and experimental results of this study on doublelapped composite-adherend joints led to the following conclusions:

A. Analytical - The finite element model developed for doublelapped joints in bending predicts high shear and normal stress concentrations at the end of the U-shaped hub. These concentrations are direct functions of the stiffness of the hub legs. Stress concentration effects may be reduced by lowering adhesive modulus, composite transverse modulus $\left(\mathrm{E}_{\mathrm{RR}}\right)$ and composite shear modulus $\left(\mathrm{G}_{\mathrm{RZ}}\right)$. The location of the high stress concentrations was experimentally verified because all failures initiated near the end of the hub; however, the trends in stress magnitudes could not be experimentally verified because all failures initiated outside the adhesive layer, the location of the calculated stresses.

B. Experimental - Bend tests of sample bonded and bonded/bolted joints exhibited failure modes dependent upon the composite adherend material. B/Al fin joints failed by adhesive peel at a working stress in the composite 75 percent of the composite $220 \mathrm{ksi}$ ( $1517 \mathrm{MPa}$ ) ultimate strength. Addition of bolts near the peel initiation region resulted in bolt failure at lower loads due to the complex tension-shear stress state. B/epoxy fin joint strengths were limited by the transverse strength of the composite. Delamination was suppressed by the addition of bolts in the stress concentration region, but the joints were still less efficient than the bonded B/AI fin joints. High-peel-strength adhesives should be used to bond double-lapped joints subjected to bending loads. 
Table I. Elastic Material Properties Used in Analysis

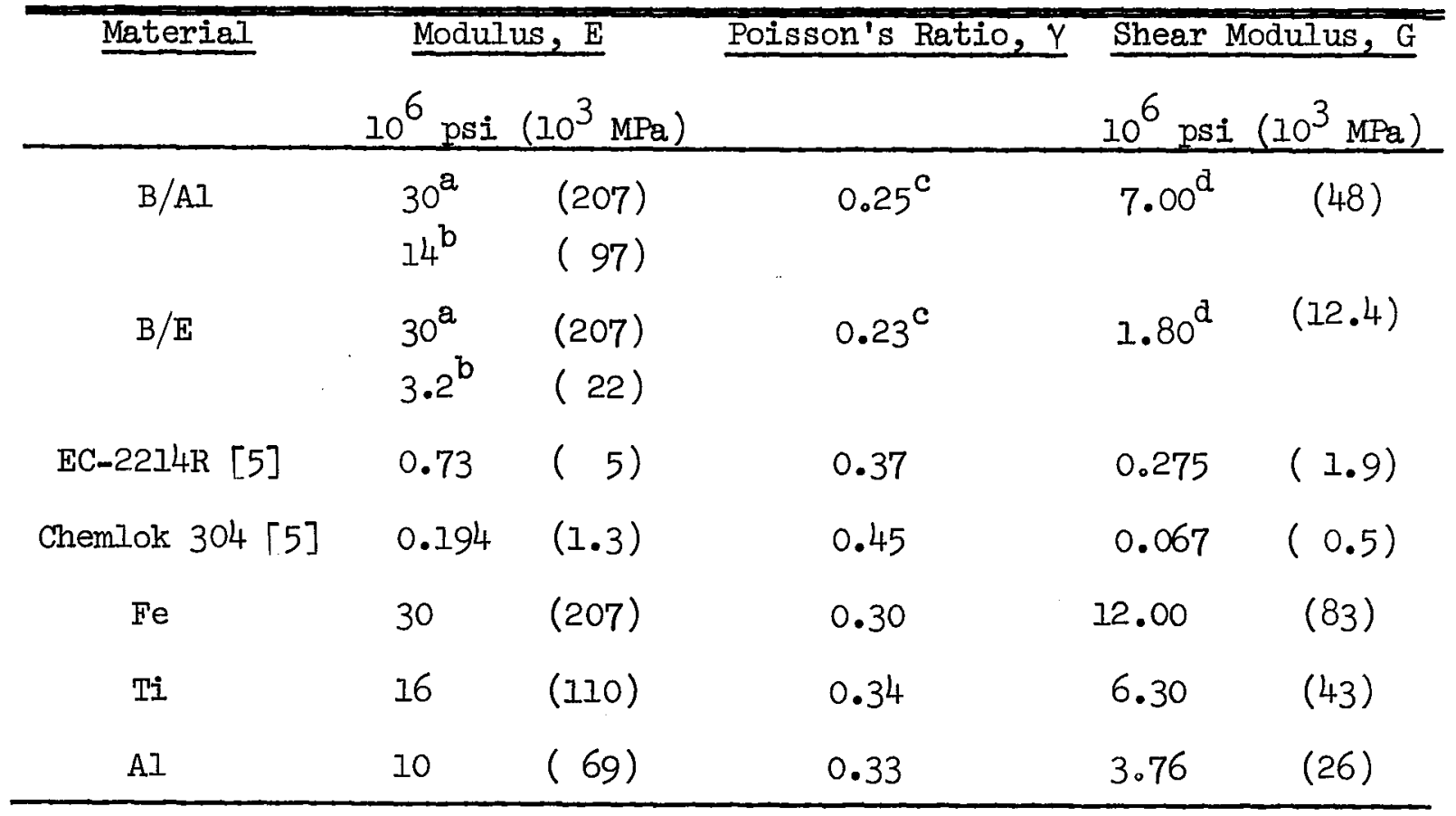

${ }^{a}$ Longitudinal modulus of transversely isotropic unidirectional composite, i.e., modulus in filament direction.

$\mathrm{b}_{\text {Transverse modulus of composite, i.e., modulus in direction normal }}$ to filaments.

'Major Poisson's ratio of unidirectional composite.

$\mathrm{d}_{\text {In-plane shear modulus. }}$

Table II. Summary of Maximum Adhesive Stresses in Subscale Fin. Results Are for the Specific Boundary Conditions Shown in Figure 2.

\begin{tabular}{|c|c|c|c|}
\hline \multicolumn{2}{|c|}{ Materials } & \multicolumn{2}{|c|}{ Maximum Stress psi ( $\mathrm{kPa})$} \\
\hline Composite & Adhesive & $\left(\mathrm{z} / \ell^{\sigma_{\mathrm{R}}}=0\right)$ & $\begin{array}{c}T_{R Z} \\
(z / \ell=0.0167)\end{array}$ \\
\hline $\mathrm{B} / \mathrm{Al}$ & $\mathrm{EC}-2214 \mathrm{R}$ & $130 \quad(896)$ & $-158 \quad(-1089)$ \\
\hline $\mathrm{B} / \mathrm{Al}$ & Chemlok 304 & $83 \quad(572)$ & $-87(-600)$ \\
\hline $\mathrm{B} / \mathrm{E}$ & $\mathrm{EC}-2214 \mathrm{R}$ & $34 \quad(234)$ & $-41(-283)$ \\
\hline $\mathrm{B} / \mathrm{E}$ & Chemlok 304 & $24 \quad(165)$ & $-26(-179)$ \\
\hline
\end{tabular}


Table III. Summary of Maximum Stresses in Adhesive for Full-Sized Fins with the Geometries and Boundary Conditions Illustrated in Figure 5.

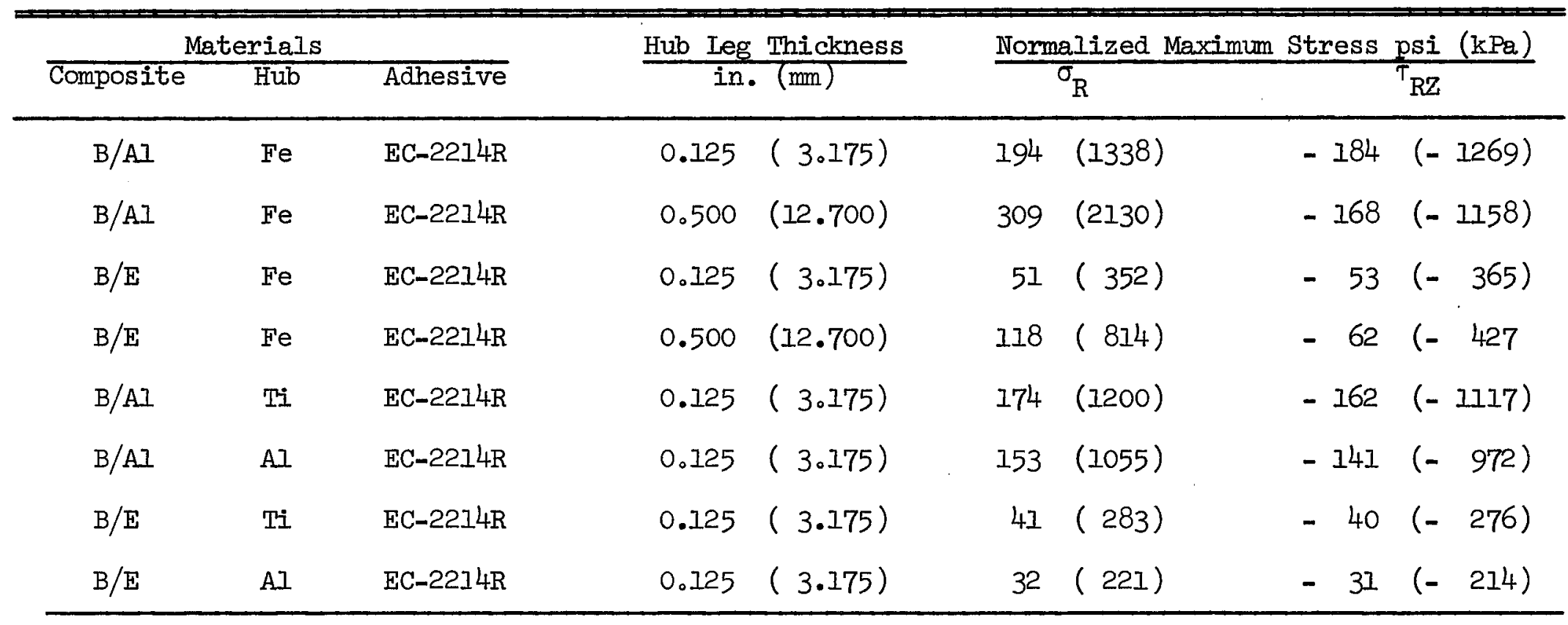

Geometrical parameters: Composite thickness $=0.4 \mathrm{in}$. (10 mm), adhesive bond thickness $=0.010$ in. $(0.25 \mathrm{~mm})$, adhesive bond length $=4.0$ in. $(102 \mathrm{~mm})$. 
Table IV. Test Results for B/Al-Steel Joints

\begin{tabular}{|c|c|c|c|c|}
\hline Joining Method & [Iti & $\begin{array}{l}\text { (N) Load } \\
\end{array}$ & $\begin{array}{c}\% \text { of Composite } \\
\text { untimate }\end{array}$ & Failure Mode \\
\hline None & 959 & $(4275)$ & 100 & $\begin{array}{l}\text { Composite in bending: ultimate } \\
\text { tensile stress } 200 \mathrm{ksi} \text { ( } 1517 \\
\mathrm{MPa} \text { ) }\end{array}$ \\
\hline EC-2214R Adhesive & 715 & (3187) & 75 & Adhesive interface-peel \\
\hline FM-53U Adhesive & 744 & (3314) & 78 & Adhesive interface-peel \\
\hline Chemlok 304 Adhesive & 466 & (2079) & 49 & Adhesive interface-peel \\
\hline EC-22I4R/2 Bolts $(15$ in.-Ib $(1.7 \mathrm{~N} \cdot \mathrm{m}))$ & 594 & $(2648)$ & 62 & Bolts \\
\hline Chemlok $304 / 2$ Bolts (15 in.-1b $(1.7 \mathrm{~N} \cdot \mathrm{m}))$ & 587 & $(2618)$ & 62 & Bolts \\
\hline 3 Bolts (15 in.-1b $(1.7 \mathrm{~N} \circ \mathrm{m}) /$ Failed Bond) & 704 & $(3138)$ & 73 & Composite across bolts \\
\hline
\end{tabular}


Table V。 Test Results for B/Epoxy-Steel Joints

\begin{tabular}{|c|c|c|c|c|}
\hline Joining Method & UIt: & $\begin{array}{l}\text { ate Load } \\
\text { (N) }\end{array}$ & $\begin{array}{c}\% \text { of Composite } \\
\text { Ultimate }\end{array}$ & Failure Mode \\
\hline None & 959 & $(4275)$ & 100 & $\begin{array}{l}\text { Composite in bending: ultimate } \\
\text { tensile stress } 200 \mathrm{ksi} \text { (1517 } \\
\mathrm{MPa} \text { ) }\end{array}$ \\
\hline EC-2214R Adhesive & 576 & $(2569)$ & 60 & Composite delamination \\
\hline Chemlok 304 Adhesivé & 453 & $(2020)$ & 47 & Adhesive interface-peel \\
\hline EC-2214R/2 Bolts $(20$ in. $-1 \mathrm{~b} .(2.6 \mathrm{~N} \circ \mathrm{m}))$ & 653 & $(2912)$ & 68 & Composite delamination \\
\hline Chemlok $304 / 2$ Bolts ( 15 in.-Ib $(1.7 \mathrm{~N} \cdot \mathrm{m})$ ) & 561 & $(2501)$ & 59 & Adhesive interface \\
\hline
\end{tabular}




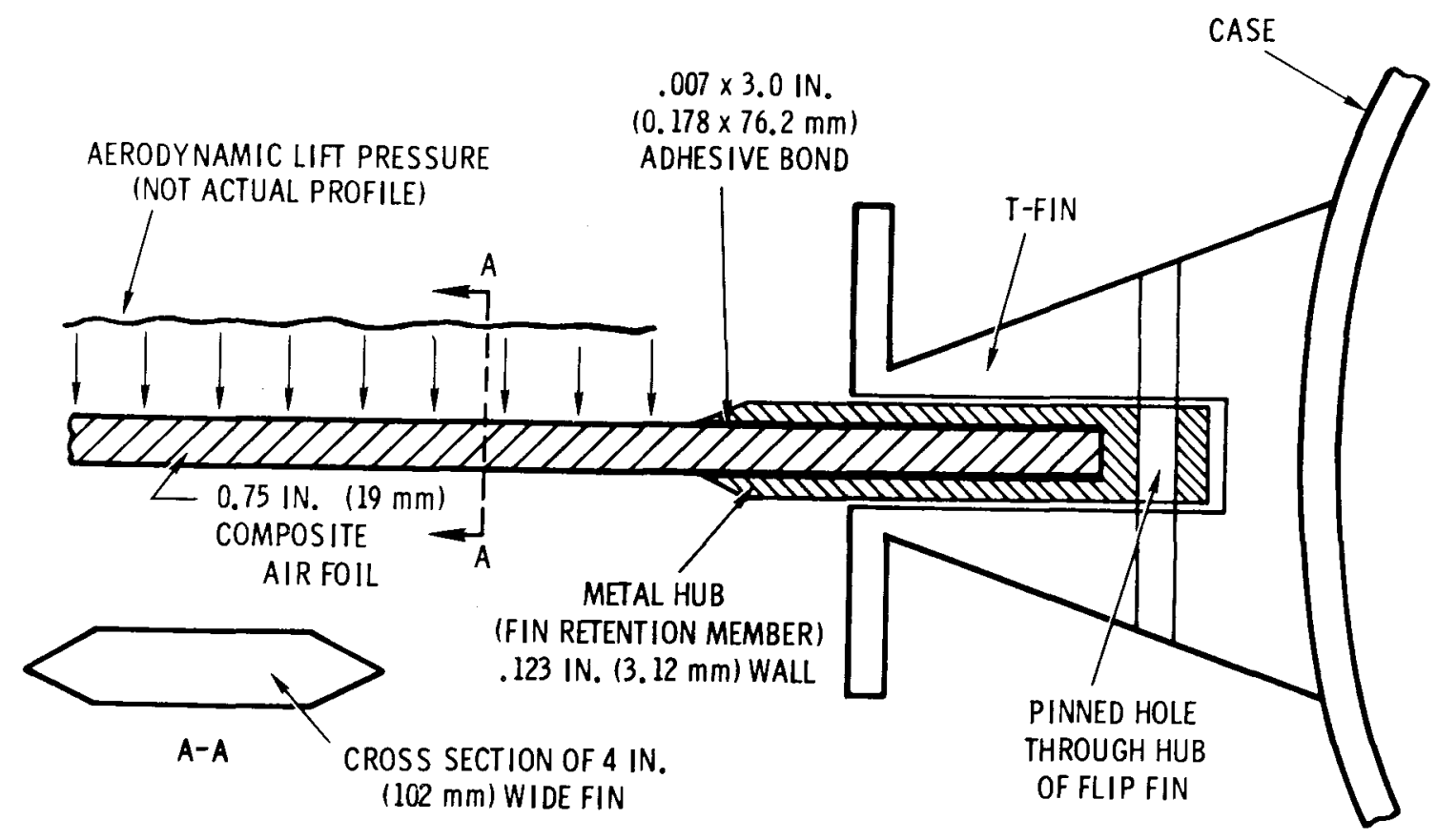

Figure 1. Fin-joint geometry (schematic).

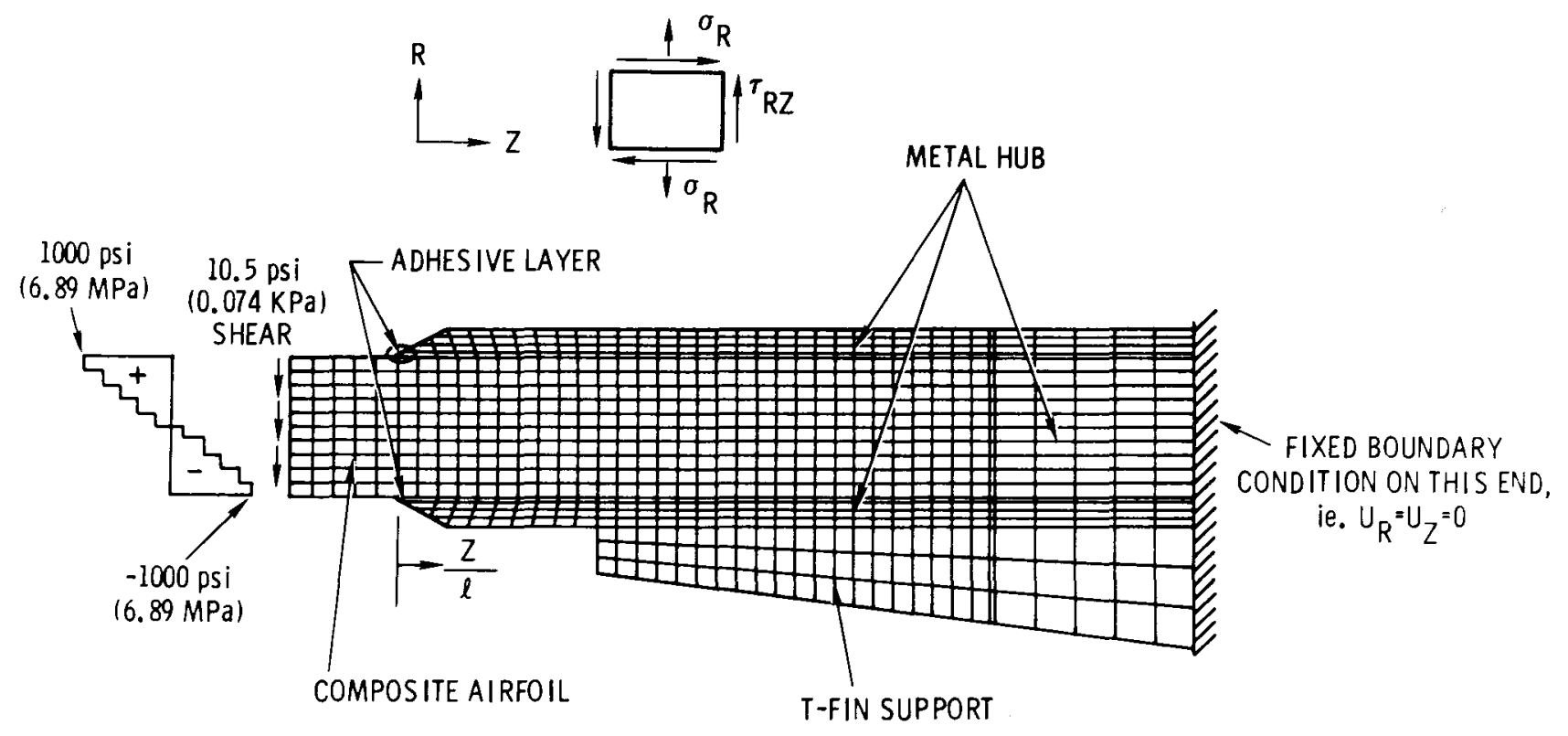

Figure 2. Finite element meshing scheme for fin-hub joint. 


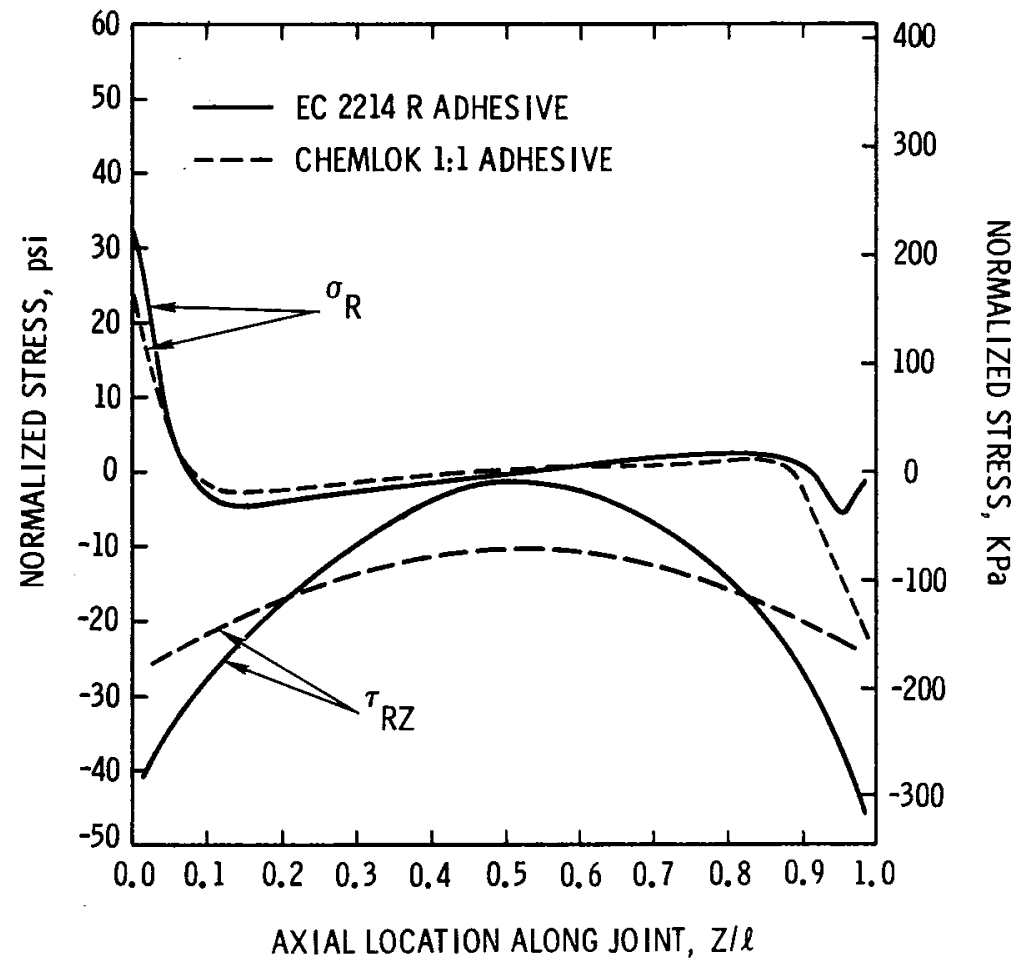

Figure 3. Predicted stress distributions for adhesivebonded double-lapped steel-B/AI joint subjected to 1000 psi bending stress on outer fibers. 


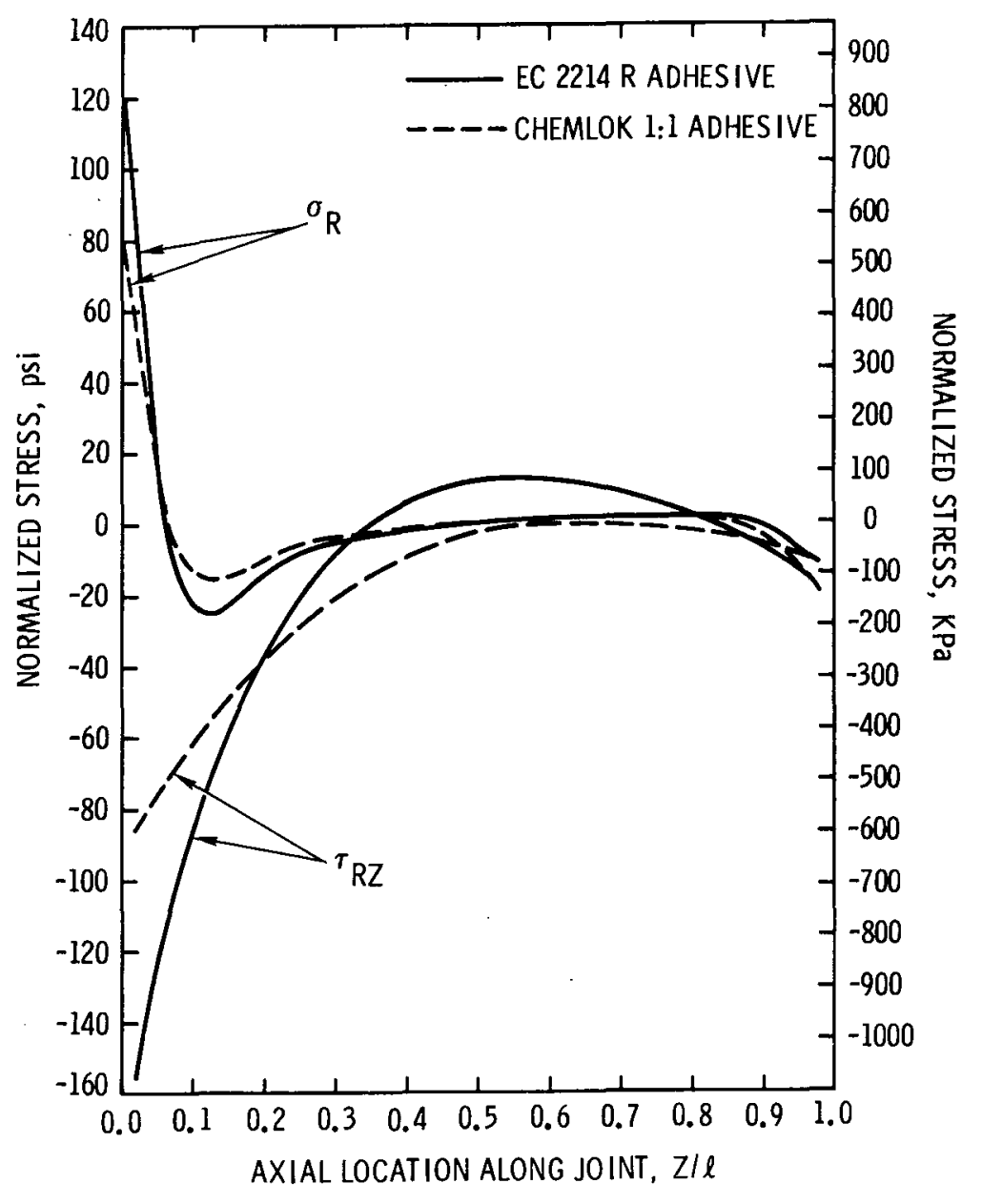

Figure 4. Predicted stress distributions for adhesivebonded double-lapped steel-B/epoxy joint subjected to 1000 psi stress on outer fibers. 


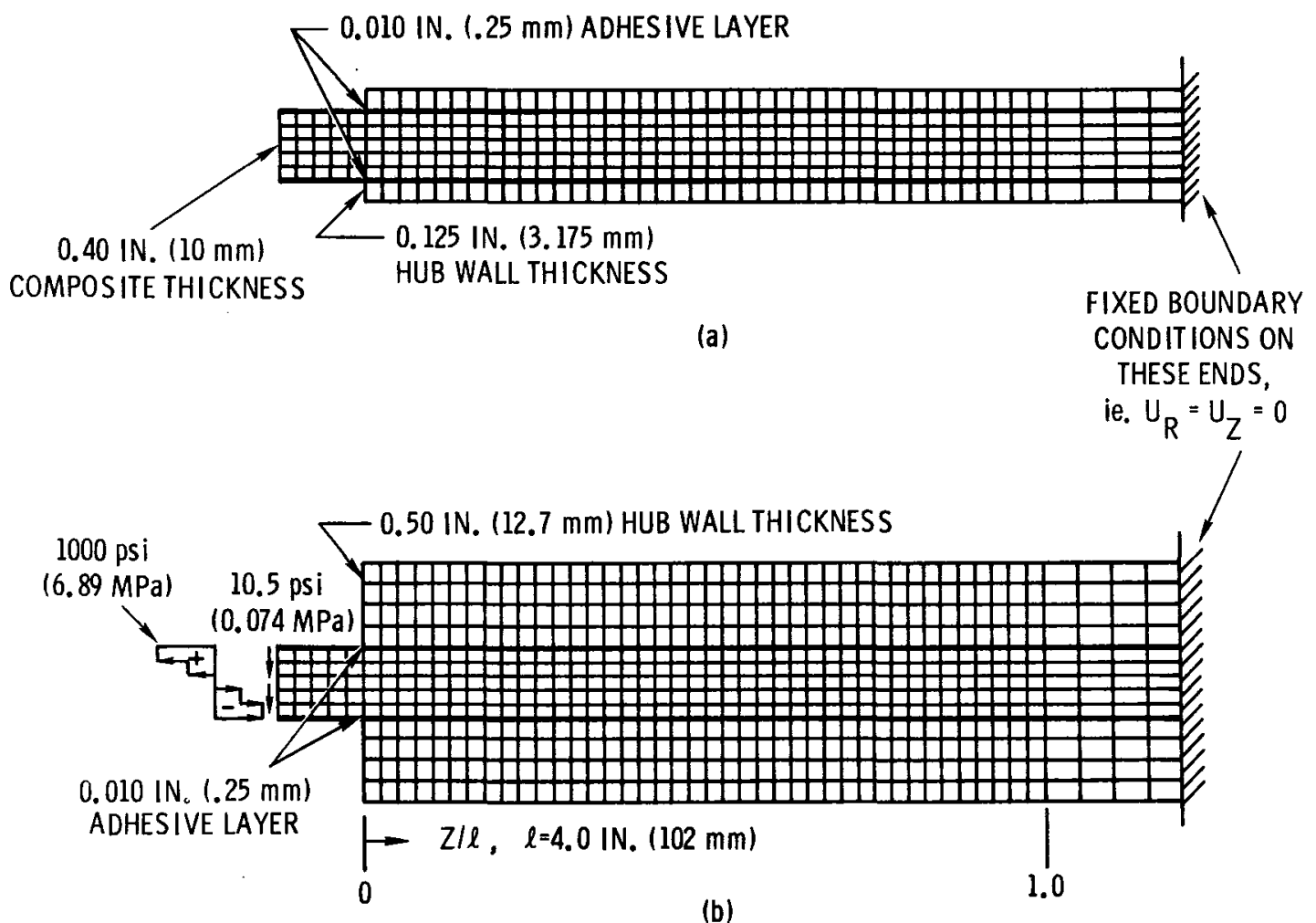

(b)

Figure 5. Finite element meshing schemes for full-sized joints. Composite thickness $=0.40$ in., adhesive thickness $=$ 0.010 in., bond length $=4.0$ in., and boundary conditions same for both. Hub wall thickness only geometrical variable in (a) 0.125 in. and in (b) 0.50 in. 


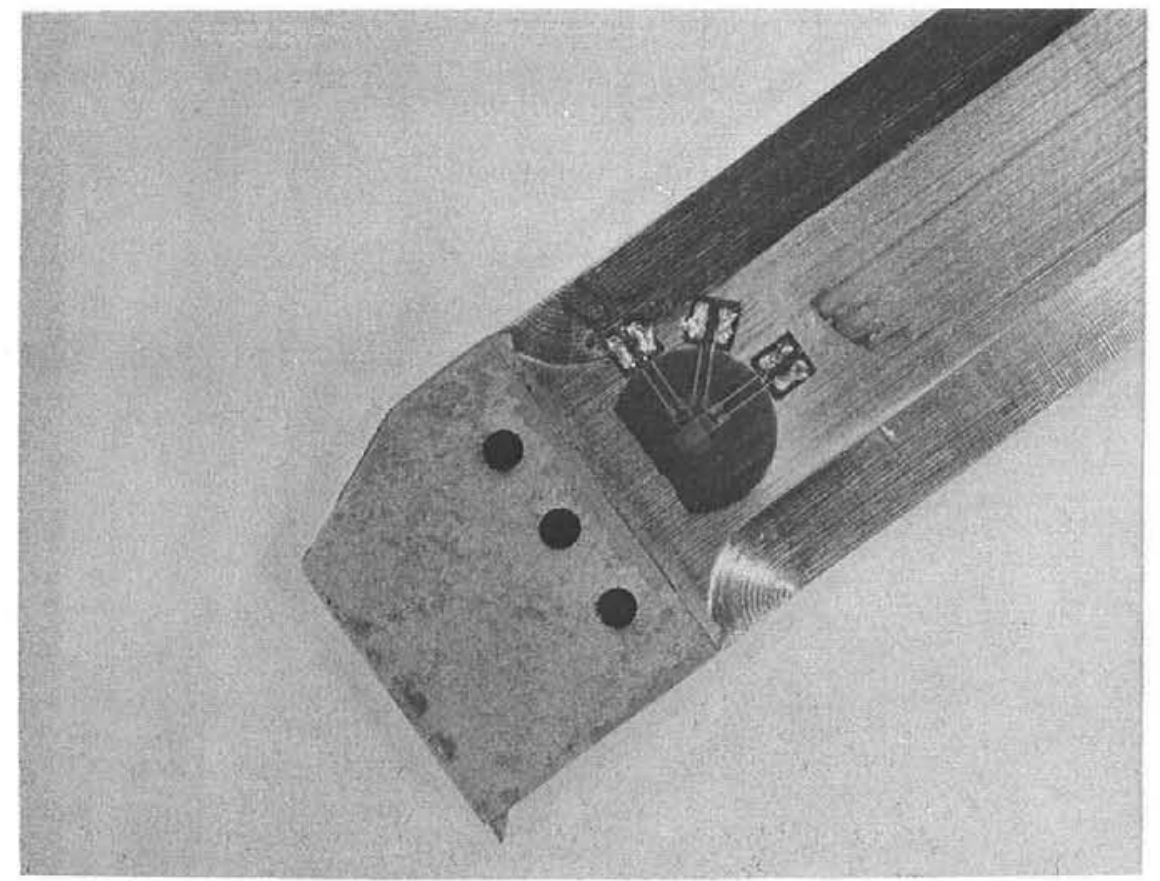

Figure 6. Fracture surface of adhesive bonded (EC-2214R) and bolted B/Al fin in airfoil geometry.

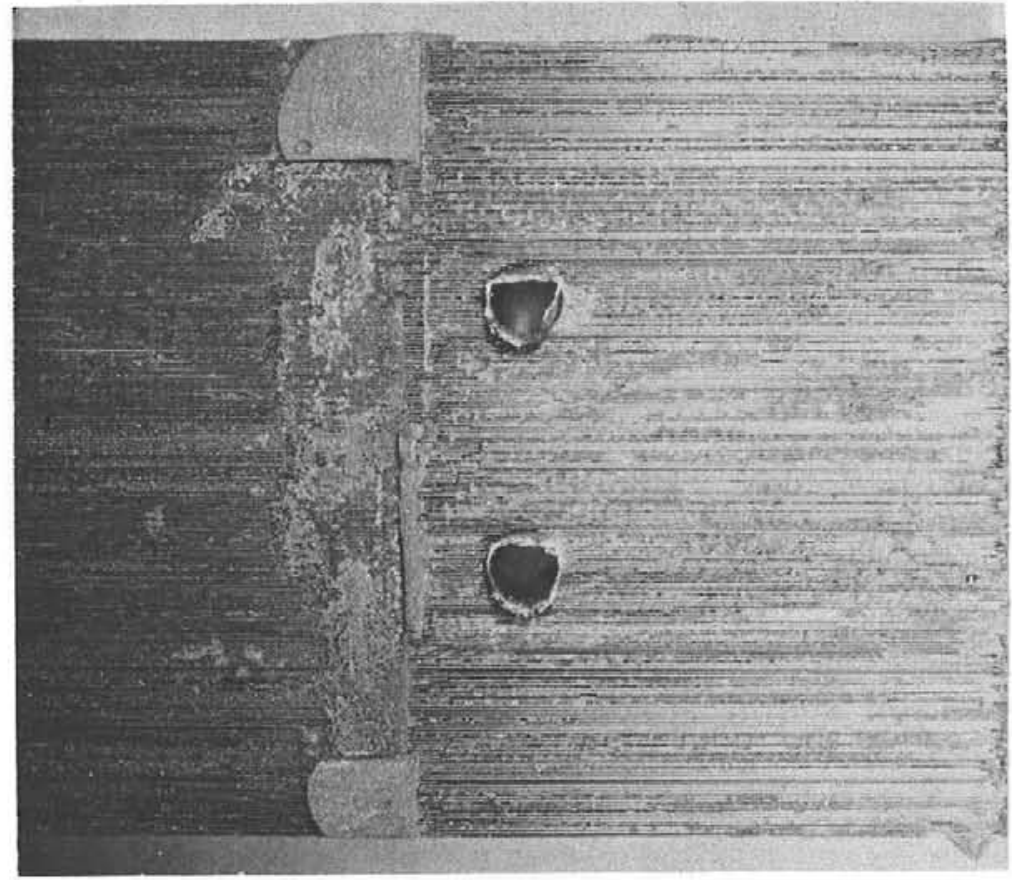

Figure 7. Delamination fracture surface of bonded (EC-2214R) and bolted joint with B/epoxy fin. 


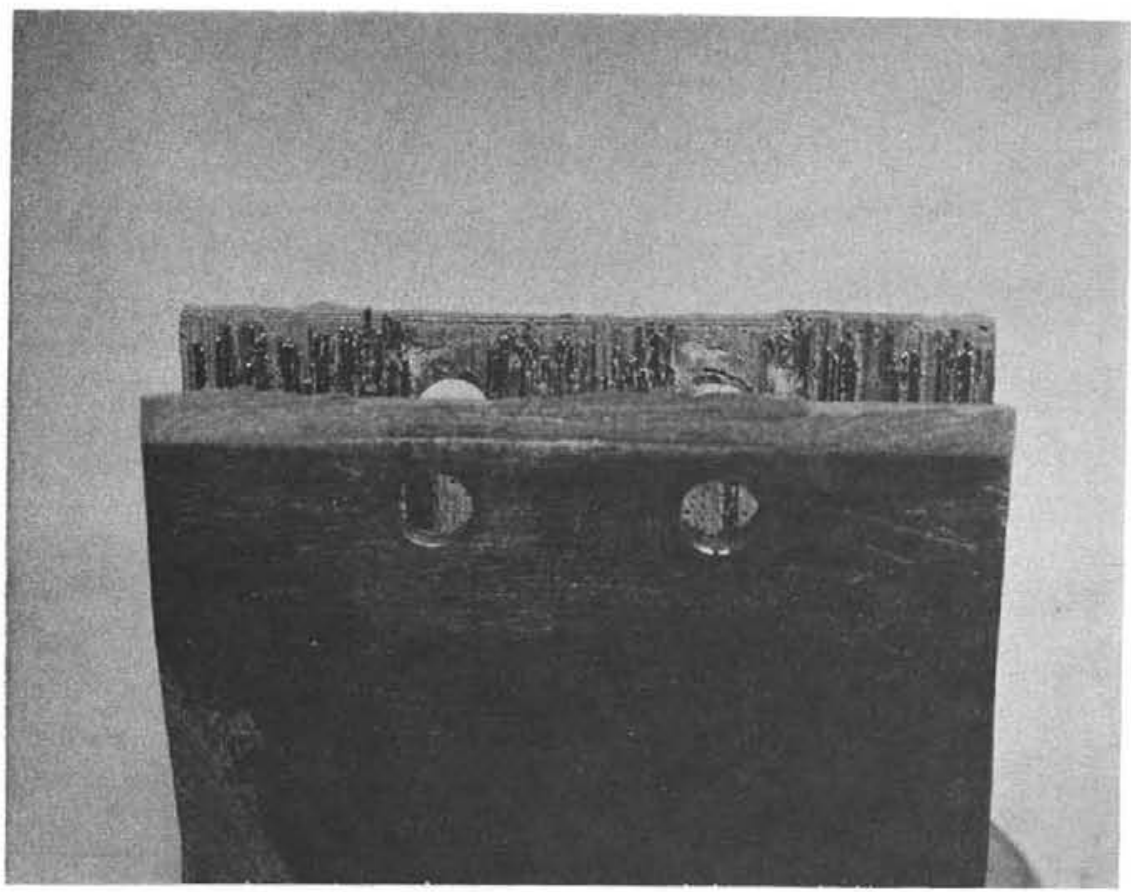

Figure 8. Hub adherend of fractured B/epoxy fin joint showing delamination failure mode. 
References

[1] W. R. Hoover and T. R. Guess, "Development of Composite Flip Fins," Sandia Laboratories Report SAND75-0322, Albuquerque, New Mexico, October 1975.

[2] I. B. Greszczuk, "Stress Concentrations and Failure Criteria for Orthotropic and Anisotropic Plates with Circular Openings," Composite Materials: Testing and Design (Second Conference), ASTM STP 497, American Society for Testing and Materials, 1972, pp. $363-381$.

[3] H. A. Perry, Adhesive Bonding of Reinforced Plastics, McGrawHill, New York, New York, 1959.

[4] E. L. Wilson and R. M. Jones, "Finite Element Stress Analysis of Axisymmetric Solids with Orthotropic, Temperature-Dependent Material Properties," Aerospace Corporation Report TR-0158 (S3816-22)-1, San Bernadino, California, September 1967.

[5] R. E. Allred and R。 J. Martinez, "Mechanical Response of Structural Adhesives," Sandia Laboratories Report, in progress.

[6] 3M Company, Adhesives, Coatings and Sealers Division, Aerospace Product Specification EC-2214 Regular, Issue No. 1, p. 6.

[7] Bloomingdale Aerospace Products, Manufacturer's Specification, FM-53 Adhesive Film, BPT53, p. 3. 
Distribution:

F. W. Jones, UCC, Y-12 Plant Attn: R. L. Huddleston C. E. Knight, Jr. I. Kovach

T. T. Chiao, I-3I, IIJ

R. G. Dong, I-424, ILL

R. H. Graham - 853, BKC

R. L. Sadler - 862, BKC

A. K. Thoeni - 862, BKC

1341 S. W. Key

Attn: J. T. Schamaun

1342 T. G. Priddy

1344 R. T. Othmer

Attn: P. P. Stirbis

3600 I. M. Berry

Attn: $3620 \mathrm{R}$. S。 Wilson

3622 T. P. Conlon

Attn: 3622-2 R.W. Weaver

3623 E. R. Frye

Attn: C. E。Albright, Jr .

F. H. Braaten

R。 M。 Rayner

5000 A. Narath

Attn: 5100 J。 Ko Galt

5200 E. H. Beckner

5400 A. W. Snyder

5700 J。H. Scott

5712 R. C。 Reuter, Jr。

5800 R. S. Claassen

Attn: 5810 R. Go Kepler

5820 R。 I. Schwoebel

5811 L。 A。 Harrah

5830 M. J。 Davis

5811 No J. DeLollis

$5813 \mathrm{~J}$ 。 G。 Curro

5840 D. M. Schuster (2)

5844 F。P.Gerstle, Jr. (2)

5844 R。E. Allred (10)

5844 B。 I. Butler

5844 R。 H。 Ericksen

5844 W. R。 Hoover

5844 K。 E。 Mead

5847 C. H. Karnes

5847 T. R. Guess (5)

8110 A. N. Blackwel1

Attn: 8113 C. S. Hoyle

8114 W. D. Zinke
8150 D. E. Gregson

Attn: 8157 G. N. Beeler

8158 A. S. Rivenes

8310 R。 H。 Meinken

Attn: 8312 D。 R. Adolphson

8314 H. J. Saxton

9352 O. J. Burchett

Attn: J. H. Gieske

9512-I R. J. Martinez

3141 C. A. Pepmueller (5)

3151 W. L. Garner (3) for ERDA/TIC (Unlimited Release)

3171-1 R. P. Campbell (25) for ERDA/TIC

8266 E. A. Aas (2) 